\section{Manufacturing}

\section{success}

Neil Alford

Materials World. Editor Nuna Staniaszek. Institute of Materials. 12/yr. Europe $£ 136$, elsewhere $\$ 283$.

SEVERAL years ago it was agreed that the British institutes representing the three main branches of materials - metals, polymers and ceramics - should join forces to form an Institute of Materials. This good idea was so straightforward that several obstacles were inevitably laid to delay the merger. Fortunately, common sense prevailed and the new institute was formed in 1992. With it came Materials World, the institute's house journal. Today the institute has 19,000 members, all of whom already receive the periodical.

Materials World, which subsumed Metals and Materials, Plastics and Rubber International and British Ceramic Journal, aims to cover all aspects of materials science, and the feature articles are therefore written so as to have broad appeal. So far, I have read each of these with interest: there is indeed a wide variation in topics covered and the standard of the articles is generally high.

In the first issue, for instance, there is an excellent article by R. J. Brook and R. A. $D$. Mackenzie on nanocomposites, as well as others on ceramic-matrix composites, metal-matrix composites and polymer composites (thus effectively offering something for everyone, whatever their particular discipline). I was especially intrigued by the article by Barry Minton of Schroder Ventures on how to make use of venture capital. In today's difficult economic climate, sensible advice on such matters is probabiy exactly what the UK materials industry needs. In this regard, John Hodgkinson's informative piece on 'smart' materials is also relevant: there is a surprising lack of work in the United Kingdom on this potentially important development, particularly compared with that done in the United States and Japan.

Indeed, a report on an overseas scienceand-technology expert mission to the United States notes the lack of strategic planning in the United Kingdom, a deficiency that the authors lay squarely at the feet of the Department of Trade and Industry. There are similar parallels here to a recent report on the US superconductivity industry. A ray of hope is found in the announcement of the formation of a new committee on smart materials. Such quasi-political comments are plainly in the interests of all materials scientists, and a refreshing aspect of the journal.

Other sections include News, Innovation, Reviews, Education (information on

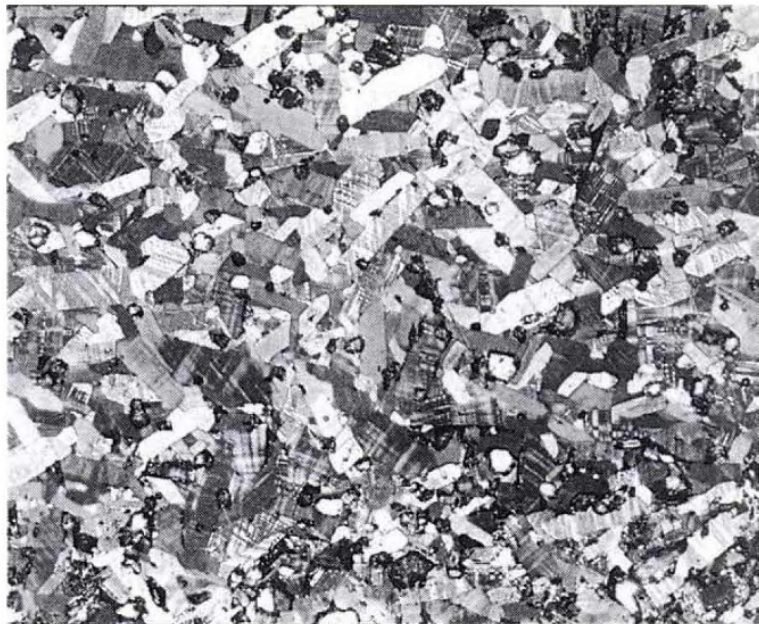

be due to the slightly drab and insubstantial paper on which it is printed).

The correspondence section contains some fairly vigorous letters and a fair number of even more robust replies. Such infusion of excitement is essential if students are to recognize materials science for what it is - a wide-ranging and fascinating area of research and development that is crucially important to the success of manufacturing industry. With its admirable aim of being cross-disciplinary and its early success in attracting some excellent features, Materials World will unceramic yttrium-barium-copper-oxide $\mathrm{YBa}_{2} \mathrm{Cu}_{3} \mathrm{O}_{6}$ (magnification $\times \sim 90$ ).

courses and so on), Product Focus, Looking Ahead (events in the materials calendar) and Classified (jobs and services). The format is a little like that of Physics World but Materials World doesn't seem to have the same sparkle (this may simply doubtedly be of great help in conveying this message.

Neil Alford is with $\mathrm{ICl}$ Superconductors, Haverton Hill Road, Billingham, Cleveland TS20 1PS, UK.

\title{
Forging ahead with an ion cast
}

\section{Stephen Mann}

BioMetals. Editor-in-chief G. Winkelmann. Rapid Communications of Oxford. $4 / y r$. £175, \$295 (institutional); £65, $\$ 110$ (personal).

BY their very nature, new journals that cater for a multidisciplinary readership often suffer the occasional anxiety attack over a sense of diminished identity. BioMetals is a new journal that has been quickly forged from the embers of the first (and last) four volumes of Biology of Metals and it is to be hoped that the new name and style give it the distinctiveness it so readily deserves. Unfortunately, the title does not help much, because the number of actual biometals known is very small $(\mathrm{Au}(0)$ deposition in bacteria is one example). But the front cover of the journal attempts to offset this ambiguity by informing us that what is really at issue is the role of metal ions in biology, biochemistry and medicine. Originally led by the bioinorganic chemists, new areas of this research are now opening up in disciplines such as molecular biology, toxicology, metabolism and nutrition. It is in this second wave of metal-ion biochemistry that BioMetals is leading the way, providing a forum for areas on the periphery of the more traditional studies of the chemical structure, bonding and reactivity of metal-ligand interactions in biological molecules.

The first five issues of BioMetals are encouraging. There is usually a minireview (about ten pages in length) followed by eight or so medium-length (four to ten pages) research papers. The review papers are excellent and, in my opinion, crucial to the future success of the journal. The research papers are generally of high scientific quality and the data (figures and tables) are well laid out. A wide range of subjects is presented, including biocoordination chemistry, metal-ion transport, toxicity and resistance, physiology and bioremediation. Studies on the role of metal ions in toxicology seem to be the most common. The papers have an international scope with India, the United States and Germany well represented. In some issues there is a page at the back on future conferences but nothing so far on new books or recent highlights in the field.

BioMetals is published by Rapid Communications of Oxford, which, as the name implies, guarantees that with fair sailing one can submit in March and be home and dry by the summer. This fullsteam-ahead approach is considered to be an important aspect of the journal; and the editors point out that refereeing standards will not be compromised. It is a little early to be able to assess whether this will be the case, but the first two volumes bode well for the future.

Stephen Mann is in the School of Chemistry, University of Bath, Bath BA2 7AY, UK. 